TrudySweeney,FLINDERS UNIVERSITY, trudy.sweeney@flinders.edu.au DeborahWest, CHARLES DARWINUNIVERSITY, deborah.west@cdu.edu.au Anthea Groessler, UNIVERSITY OF QUEENSLAND, a.groessler@uq.edu.au Aeron Haynie, UNIVERSITY OF NEW MEXICO, ahaynie@unm.edu Bettie Higgs, UNIVERSITY COLLEGE CORK, b.higgs@ucc.ie Janet Macaulay, MONASH UNIVERSITY, janet.macaulay@monash.edu Lucy Mercer-Mapstone, UNIVERSITY OF QUEENSLAND, 1.mercermapstone@uq.edu.au Michelle Yeo, MOUNT ROYAL UNIVERSITY, myeo@mtroyal.ca

\title{
Where's the Transformation? Unlocking the Potential of Technology-Enhanced Assessment
}

\begin{abstract}
This study provides insight into technology-enhanced assessment (TEA) in diverse higher education contexts. The effectiveness of using technology for assessment in higher education is still equivocal, particularly in regard to evidence of improvements in student learning. This empirical research explores the affordances that technology offers to assessment for transforming student learning. A systematic literature review, guided by an analytic survey tool, was used to identify and interrogate recent scholarly articles published in 19 international journals. From a total of 1713 articles, 139 articles were identified as being focused on the use of technology for assessment. The analytic tool guided the rigorous exploration of the literature regarding the types of technology being used, the educational goal, the type of assessment, and the degree of "transformation" afforded by the technology. Results showed that, in the sample investigated, TEA is used most frequently for formative peer learning, as part of the task design and feedback stages of the assessment cycle, and that social media has been a major affordance for this. Results are discussed with a view to fostering a future culture of inquiry and scholarship around TEA in higher education.
\end{abstract}

\section{KEYWORDS}

assessment, technology, learning, enhanced, transformed

\section{INTRODUCTION}

Assessment and feedback are at the center of learning, but are cited as the "single biggest source of student dissatisfaction within the higher education experience" (Ferrell, 2012, p. 3). Although there have been significant changes in the way we think about student learning in higher education, such as a more student-centered paradigm, there has been a much slower shift in changing assessment and feedback methods (Nicol \& Macfarlane-Dick, 2006). 
Calls for assessment reform center on the need to keep pace with current pedagogical, cultural, and technological developments affecting teaching and learning (JISC, 2010).

Developments in learning sciences have supported the claim that cognitive abilities are 'developed' through socially supported interactions (Vygotsky, 1978) and that learning is an active process of mental construction and sense-making. They have also deepened our understanding of the importance of accessing higher order competencies, peer-assessment and self-regulation of learning (Oldfield, Broadfoot, Sutherland, \& Timmis, 2012). Concurrently, digital technologies have become integral to higher education with an array of tools available to provide administrative and pedagogical affordances that offer more "personalised, instantaneous or engaging assessment experiences" (Oldfield et al., 2012, p. 1).

It is imperative to look to different ways of engaging and empowering students in assessment (Nicol \& McFarlane-Dick, 2006; Boud \& Associates, 2010). The Higher Education Academy, UK (HEA, 2012) contends that there should be a shift in balance from summative to formative assessment and from assessment of learning to assessment for learning. Through improving and engaging students with assessment, we have the capability to improve student learning (Gibbs \& Simpson, 2004). However, Price and Kirkwood (2014) concluded that the use of technology often replicates existing assessment practices rather than embracing transformative practices. The rapid growth of online and hybrid courses, technology-enhanced classrooms, and other forms of educational technology, are often promoted as if technological innovation is synonymous with improved learning. However, there is little evidence that technology has improved tertiary level student learning or, if so, to what extent (Price \& Kirkwood, 2014).

The aim of this study is to explore technology enhanced assessment (TEA) and employ existing frameworks to shed light on its potential to enhance or transform student learning.

\section{ASSESSMENT AND FEEDBACK}

The terms 'assessment' and 'evaluation' are used differently, and sometimes interchangeably, across international contexts. In this paper we use the term 'assessment' to mean the measuring of student learning and attainment of learning outcomes at the unit/subject or program level.

Assessment is most effective when it is central to curriculum design (Boud \& Associates, 2010) which engages and motivates learners to take ownership of their learning (JISC, 2010). This requires a combination of feedback and feed-forward to ensure effective developmental impact on learning (Nicol 2013, 2014). Feedback focuses on a learner's current performance and may simply justify the grade awarded, whereas, feed-forward offers constructive guidance on how to do better in future work (Ferrell, 2013).

The identification of assessment and feedback principles informed by what is known about good practice can enable practitioners to "identify where the application of technology may add educational value" (JISC, 2010, p. 14). The Re-Engineered Assessment Practices project (REAP, 2007) gave rise to 12 principles for transforming assessment and feedback. Nicol (2009) makes the point that the principles are to be interpreted within a model of self-regulated learning in which the aim is to develop "students' own assessment skills so that, over time, they become less dependent on others to correct their work and more able to judge the quality of work themselves" (Ferrell, 2013, p. 8 ). The principles intersect and need to be adapted to different disciplines and contexts, and need not all be applied to every assessment design (JISC, 2010). 
According to Nicol (2009, p. 5), good assessment and feedback practice should:

- Help clarify what good performance is (goals, criteria, expected standards);

- Encourage 'time and effort' on challenging learning tasks;

- Deliver high quality feedback information that helps learners to self-correct;

- Provide opportunities to act on feedback to close any gap between current and desired performance;

- Ensure that summative assessment has a positive impact on learning;

- Encourage interaction and dialogue around learning (peer and teacher-student);

- Facilitate the development of self-assessment and reflection in learning;

- Give choice of topic, method, criteria, weighting, or timing of assessments;

- Involve students in decision-making about assessment policy and practice;

- Support the development of learning groups and communities;

- Encourage positive motivational beliefs and self-esteem; and

- Provide information to teachers that can be used to help shape their teaching and subsequent assessment tasks.

\section{TECHNOLOGY-ENHANCED ASSESSMENT (TEA)}

Interest in TEA has increased in higher education as a strategy to enable peer-, self- and teacher-assessment, and respond to assessment challenges including distance and flexible learning, large student enrollments (Oldfield et al., 2012; Whitelock \& Watt, 2008), and the provision of "constructive, timely and 'easy to understand' feedback" (Whitelock, Gilbert, \& Gale, 2011, p. 2). The transformative effects of TEA are more likely when there is a clear educational intent, and when the use of technology is skillfully contextualized (JISC, 2010). Oldfield et al. (2012) suggest that digital technologies could significantly change assessment through strategies such as employing multiple types of assessment to accommodate learner choice, developing new ways to treat summative assessment, capturing various skills and competencies such as peer interaction and collaboration, and using data analytics to inform assessment practices.

JISC's (2010) Effective Assessment in the Digital Age, defines TEA as the "Use of technology to extend or add value to assessment and feedback processes" (p. 57). This definition is predicated on the idea that educational theory and pedagogy relevant to assessment are underpinning elements. In their exploration of TEA, JISC identify trends that have emerged over the last decade and describe the immediate future. Noteworthy is the shift in focus from institutional ownership of assessment and feedback towards greater learner participation and efficiency in practices, whilst still upholding the value systems that surround assessment. Critical to this process is the idea that, "Innovations first need to be tested against principles of effective assessment and feedback, and their merits considered within the disciplinary context in which they are used" (JISC, 2010, p. 54).

\section{THEORETICAL FRAMEWORK}

The Technological Pedagogical and Content Knowledge (TPACK) framework draws attention to the critical intersection between educators' technology, pedagogy and content knowledge. The framework emphasizes the need for educators to develop sensitivity to the dynamic, 
transactional relationships between these components "to understand the variance in levels of technology integration” (Koehler \& Mishra, 2009, p. 9).

The Substitution, Augmentation, Modification and Redefinition (SAMR) model, whilst considered by some to be controversial (O'Hagan, 2015), is widely recognized and used in the educational technology field (JISC, 2015). JISC (2015) suggests the SAMR model is a useful taxonomy to explore the purpose and practice of using digital technologies in curricular design. The taxonomy levels derived from Puentedura (2010) are:

- Substitution: digital technologies replace other tools with no functional improvement;

- Augmentation: digital technologies replace other tools but with functional improvement;

- Modification: technology is used for significant task redesign; and

- Redefinition: new tasks are created that were previously not possible.

Substitution and Augmentation are categorized as technological enhancements, and Modification and Redefinition as technological transformations (Puentedura, 2010). Technological innovations alone should not be assumed to enhance or transform assessment and feedback practices. Together, the SAMR model and the TPACK framework, underpinned by the principles for transforming assessment and feedback practice (Nicol, 2009), provide a useful set of parameters to explore TEA.

\section{RESEARCH DESIGN}

This study explores the use of technology in relation to assessment and feedback practices to address the following questions:

1. What technologies are being used?

2. How are these technologies enhancing or transforming assessment and feedback practice?

The method of a systematic literature review was selected to sample scholarly journals focused on teaching and learning in higher education to identify what technologies are being used in TEA and highlight examples of transformation aligned with the Redefinition level of the SAMR model. A survey-type data-collection instrument was developed to allow for the rigorous analysis of the journal articles. This instrument consisted of 30 questions, hosted on the SurveyMonkey online platform, that the authors used with each journal article to collect the dataset. ${ }^{1}$ The survey questions, format, and delineated responses were constructed drawing on a number of frameworks including Tight (2012) in terms of methods, JISC (2010) on good practice in technology-enhanced assessment, Price and Kirkwood (2014) on the role of evidence in informing practice, the TPACK framework (Mishra \& Koehler, 2006) to consider the teacher knowledge required for effective technology use in curriculum design, and the SAMR model (Puentedura, 2010) to consider the taxonomy of educational technology. The survey included the following question sets:

1. Demographic data including year, country, approach (theoretical/descriptive/research), and methods; breadth of study, sample size, level of analysis, theoretical underpinning, and discipline;

2. Type of assessment (formative or summative; teacher or peer; with or without feedback);

3. Educational theory, pedagogical approach, and educational goal; and

4. Type of technology, technology use, and affordances for assessment.

Questions were constructed with delineated responses to allow for quantitative analysis.

44 Sweeney, T., West, D., Groessler, A., Haynie, A., Higgs, B., Macaulay, J., Mercer-Mapstone, L., \& Yeo,

M. (2017) Where's the transformation? Unlocking the potential of technology-enhanced

assessment. Teaching Learning Inquiry, 5(1). http://dx.doi.org/10.20343/teachlearninqu.5.1.5 
Open-ended questions were included to capture researcher insights and justification for choice of responses.

The survey instrument was trialled by the current authorship team using two journal articles. Based on the trial, the instrument was refined iteratively to ensure clarity of meaning of questions and response categories. The team members then analyzed articles individually. Finally, accuracy of analysis was facilitated by group discussion and peer-reading of selected articles.

Decisions on which journals to review began with an existing list of generalist and disciplinary SoTL journals which was previously compiled as part of an Australian funded SoTL project (Grant, 2013). This list was used as a starting point and then broadened to include journals focused on educational technology as well as other journals based on team members' disciplinary knowledge. Team members each selected and reviewed three journals, including one from their disciplinary area (aligning with good practice advocated by JISC, 2010), published for the period from January 2014 to January 2016 inclusive. This resulted in a select list of 19 higher education journals focused on teaching and learning and categorized into three key areas: non-discipline specific, discipline specific, and technology. Choice of journals to review from the more comprehensive list was based on efforts to ensure a mix from various perspectives and countries, and also based on team members' interest, disciplinary background, and knowledge of the relevance and status of the journal.

Data collection began with team members reviewing the abstract and keywords of every article across the specified time period. Articles indicating some focus on assessment and the use of technology via the keywords and abstract were further analyzed using the data collection instrument. The resulting data were cleaned to ensure duplicates were removed and the data were complete. Of the 1713 abstracts reviewed from 19 journals, 139 articles (8\%) met the inclusion criteria and were further analyzed. Table 1 provides an overview of the journals reviewed by category, the number of article abstracts reviewed, and those selected for further analysis.

Table 1. Summary of higher education journals reviewed

\begin{tabular}{l|l|l}
\hline NON-DISCIPLINE SPECIFIC & $\begin{array}{l}\text { TOTAL } \\
\text { ARTICLES }\end{array}$ & $\begin{array}{l}\text { SELECTED } \\
\text { ARTICLES }\end{array}$ \\
\hline International Journal for the Scholarship of Teaching and Learning & 42 & 3 \\
\hline Journal of University Teaching and Practice & 54 & 4 \\
\hline Teaching in Higher Education & 148 & 3 \\
\hline Assessment and Evaluation in Higher Education & 158 & 14 \\
\hline Active Learning in Higher Education & 37 & 10 \\
\hline New Directions in Teaching and Learning & 60 & 1 \\
\hline Teaching \& Learning Inquiry & 37 & 5 \\
\hline Higher Education Research \& Development & 144 & 3 \\
\hline
\end{tabular}


Table 1. Summary of higher education journals reviewed (continued)

\begin{tabular}{l|c|c}
\hline TECHNOLOGY & $\begin{array}{l}\text { TOTAL } \\
\text { ARTICLES }\end{array}$ & $\begin{array}{l}\text { SELECTED } \\
\text { ARTICLES }\end{array}$ \\
\hline Research in Learning Technology & 47 & 7 \\
\hline Journal of Teaching and Learning with Technology & 30 & 14 \\
\hline Australasian Journal of Educational Technology & 94 & 22 \\
\hline British Journal of Educational Technology & 225 & 14 \\
\hline DISCIPLINE SPECIFIC & & 2 \\
\hline Pedagogy & 90 & 2 \\
\hline College English & 112 & 4 \\
\hline Biochemistry and Molecular Biology Education & 160 & 15 \\
\hline Nurse Education Today (2016 only) & 132 & 4 \\
\hline CBE - Life Sciences Education & 67 & 12 \\
\hline $\begin{array}{l}\text { International Journal of Innovation in Science and Mathematics } \\
\text { Education }\end{array}$ & 24 & 0 \\
\hline Learning and Teaching in the Social Sciences & 1713 & 139 \\
\hline Total number of journal articles in sample & & 2 \\
\hline
\end{tabular}

Frequencies (count and percentages) were calculated for the dataset. Where questions included an open response 'other' option, responses were manually coded into either new categories for that question, or into existing categories where appropriate. Open response questions underwent a basic thematic analysis to highlight emerging themes across responses.

It should be noted that the list of journals reviewed in this study was limited in terms of the country of origin and breadth of disciplines suggesting that the findings should not be generalized beyond this dataset. The study could be extended through the review of additional journals within the field as well as across disciplines. An additional limitation is that, although the study design endeavored to reduce interpretative differences between those reviewing the articles, the data recording nonetheless was undertaken by multiple researchers.

\section{FINDINGS}

This section briefly describes the dataset then presents the findings aligned with the two research questions.

\section{The dataset}

Of the 1713 articles reviewed across 19 journals, 8\% (139) indicated a focus on assessment and technology. ${ }^{2}$ The articles reviewed were spread over the sample period with $41 \%$ (57) in 2014, $47 \%$ (65) in 2015, and 12\% (17) in 2016 (encompassing January only). Sixty percent (83) of articles 
reported on teaching interactions within a blended mode (face-to-face teaching combined with online elements), while $27 \%$ (37) were focussed on face-to-face teaching, and $6 \%$ (8) were fully online. The 139 articles inform our study which seeks to answer two questions about affordances and good practices in TEA.

\section{Question 1: What technologies are being used?}

To explore this question, the articles in the dataset were analyzed to identify the types of technology used to facilitate assessment and feedback. Technologies reported were grouped into broad categories. Table 2 shows all categories with frequency greater than $2 \%$. Categories include a variety of relevant applications or affordances (e.g., social media includes applications such as Twitter, Facebook and wikis). The 'learning management system' category is somewhat problematic, as such systems can be used for a variety of purposes including delivery of content, questionnaires and social interaction. However, this category was recorded in the context of assessment, technology and student learning. Multiple technologies were recorded for some articles where reference was made to their use in assessment. Technologies with frequency less than $2 \%$ included data analytics and MOOCs.

Table 2. Type of technology used for assessment

\begin{tabular}{l|c|c}
\hline TECHNOLOGY & PERCENTAGE \% (OF 139) & NUMBER OF ARTICLES \\
\hline Social media & 27 & 37 \\
\hline Learning management system & 24 & 35 \\
\hline Visual presentation tools & 13 & 18 \\
\hline Online questionnaires & 11 & 15 \\
\hline Mobile technology & 10 & 14 \\
\hline Simulation & 8 & 8 \\
\hline Augmented reality & 6 & 8 \\
\hline Highly interactive virtual environments & 6 & 7 \\
\hline E-examinations & 5 & 6 \\
\hline E-portfolios & 4 & 5 \\
\hline Electronic voting systems & 4 & 4 \\
\hline Cloud computing & 3 & \\
\hline Total number of journal articles in sample =139 & & 11 \\
\hline
\end{tabular}




\section{Question 2: How are these technologies enhancing or transforming assessment and feedback practice?}

Exploration of how the technology was being used to enhance or transform assessment and feedback practice accepted that "effective assessment assumes a theory of learning and a model of cognition" (Nicol, 2008, p. 1) and that transformative effects of TEA are more likely when educators have a clear educational intent (JISC, 2010). Therefore, this study sought to identify the educational goals, educational theories, and pedagogical approaches underpinning the way in which specific technologies were being used for assessment and feedback practice.

Sixty-one per cent (85) of articles were explicit about their underpinning theoretical framework with 20 learning theories identified. Constructivism (or a constructivist theory) was most often cited (11\%) followed by cognitivist, situational, community of practice, activity, Kolb experiential, elaboration, and gaming learning theories.

Of the articles analyzed, 60\% (84) referred to a specific pedagogical approach, with a wide range being named. Peer-learning or peer-assessment was cited in $22 \%$ (31) of articles. Other pedagogies named included simulation-based learning (9\%), problem-based learning (4\%), and flipped classroom approaches $(3 \%)$.

In terms of the educational goals being pursued, the broad aim of improving student learning was identified in $64 \%$ (89) of the dataset. Table 3 identifies the specific goals where they were stated in articles.

Table 3. Educational goals being pursued

\begin{tabular}{l|l|c}
\hline GOAL & PERCENTAGE \% & NUMBER OF ARTICLES \\
\hline Increase collaboration & 37 & 52 \\
\hline Promote self and peer assessment/feedback & 37 & 52 \\
\hline Link to employers/professional networks & 14 & 20 \\
\hline Improve efficiency & 14 & 20 \\
\hline Develop technological skills/digital literacy & 9 & 12 \\
\hline Manage large classes & 7 & 10 \\
\hline Standardize assessment practice & 7 & 10 \\
\hline Improve student confidence/motivation & 6 & 9 \\
\hline
\end{tabular}

Note: articles could identify multiple goals

The articles analysed identified a variety of ways in which technology was being used to achieve educational goals through assessment and feedback practices. Table 4 shows a summary of how these uses align with Nicol's (2008) stages in the assessment cycle: Task Design, Assessment and Interpretation, and Feedback and Grading. 
Table 4. Summary of how technology supports assessment and feedback practices based on Nicol's (2008) stages in the assessment cycle

\begin{tabular}{|c|c|c|}
\hline DESCRIPTION & PERCENTAGE\% & \# OF ARTICLES \\
\hline \multicolumn{3}{|l|}{ STAGE 1 - TASK DESIGN } \\
\hline $\begin{array}{l}\text { Provides greater flexibility in the timing of assessment to give students } \\
\text { more control and enhance self-regulation. }\end{array}$ & 40 & 55 \\
\hline Makes it easier for teachers to monitor and track learner progress. & 25 & 35 \\
\hline Tailors/personalizes assessments to meet individual student needs. & 14 & 19 \\
\hline $\begin{array}{l}\text { Enables students to develop knowledge, skills and attitudes from a } \\
\text { much wider network. }\end{array}$ & 37 & 51 \\
\hline $\begin{array}{l}\text { Improves the efficiency of the administration of assessment processes } \\
\text { making them less time consuming. }\end{array}$ & 22 & 30 \\
\hline $\begin{array}{l}\text { Allows teachers to orchestrate objective testing and encourage } \\
\text { students to spend more time 'on task.' }\end{array}$ & 17 & 23 \\
\hline Makes assessments more authentic and enriching. & 36 & 49 \\
\hline \multicolumn{3}{|l|}{ STAGE 2 - ASSESSMENT AND INTERPRETATION } \\
\hline $\begin{array}{l}\text { Increases the validity of assessment tasks by sampling the knowledge, } \\
\text { skills, and attitudes that students are expected to develop. }\end{array}$ & 21 & 29 \\
\hline $\begin{array}{l}\text { Charts students' developing understanding to support learning not } \\
\text { just certify achievement. }\end{array}$ & 19 & 26 \\
\hline \multicolumn{3}{|l|}{ STAGE 3 - FEEDBACK AND GRADING } \\
\hline Clarifies what good performance is. & 31 & 43 \\
\hline $\begin{array}{l}\text { Facilitates the development of self-assessment and reflection in } \\
\text { learning. }\end{array}$ & 39 & 54 \\
\hline Delivers high quality feedback that helps students self-correct. & 32 & 43 \\
\hline Encourages teacher and peer dialogue around learning. & 35 & 48 \\
\hline Encourages positive motivational beliefs and self-esteem. & 14 & 19 \\
\hline $\begin{array}{l}\text { Provides opportunities to close the gap between current and desired } \\
\text { performance. }\end{array}$ & 31 & 43 \\
\hline $\begin{array}{l}\text { Provides information to teachers that can be used to help shape their } \\
\text { teaching. }\end{array}$ & 26 & 36 \\
\hline
\end{tabular}

Note: articles could identify multiple stages 
The most frequently described constraints related to unlocking the potential of TEA were student resistance $16 \%(21)$, technical glitches $10 \%$ (13), and implementation issues $8 \%(10)$. In terms of faculty perspectives, a lack of financial resources $2 \%$ (3), and change management (cultural shift) issues $2 \%$ (2), were highlighted. In order to reduce student resistance, some articles suggested there was a need for students to know the purpose of the assessment and be well versed in the technology that supports it, as technology needs to perform seamlessly with tasks to be beneficial.

Whether or not TEA was 'transforming' assessment and feedback practices was considered using the SAMR model. The levels of the SAMR model, outlined previously, were used to examine how the technology was being used for assessment and feedback practices (figure 1). In 12\% (16) of articles the innovation was simply substituting the technology for the traditional mode of assessment without any added benefits being stated. Forty-one percent of articles (57) indicated the technology allowed some functional improvement, and in 30\% (41) a significant task redesign took place. Seventeen percent of studies (23) gave evidence for some kind of redefinition of assessment, transforming student learning, or the students themselves.

Figure 1. Journal articles in this study mapped using the SAMR model

Enhancement

$$
45
$$$$
40
$$$$
35
$$$$
30
$$$$
25
$$$$
20
$$$$
15
$$$$
10
$$$$
5
$$$$
0
$$

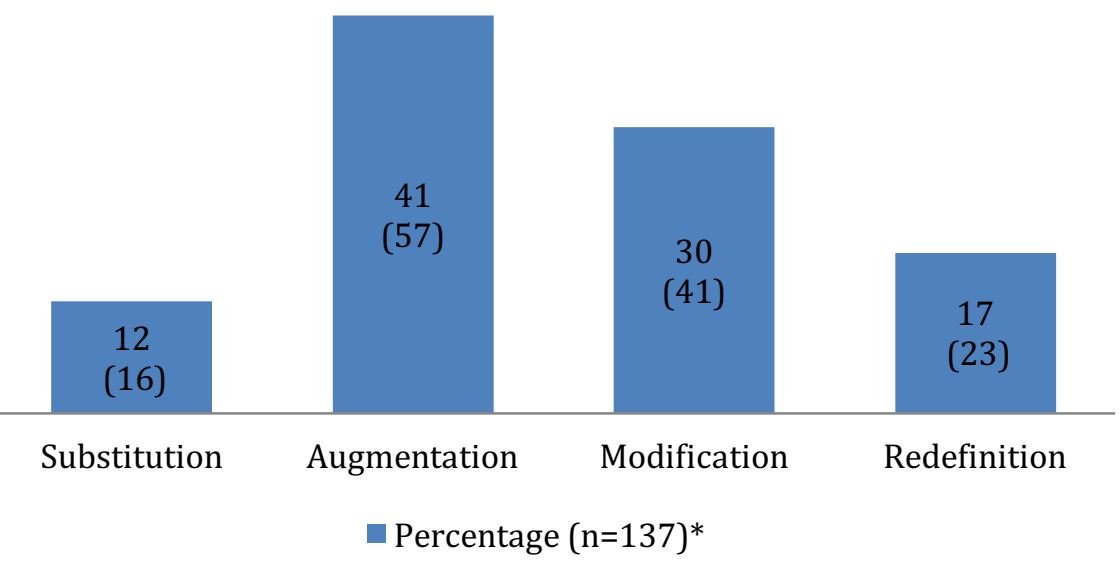

${ }^{*}$ Note: Only 137 articles were appropriate to be classified in this way

In summary, $47 \%$ of the articles were classified as Modification or Redefinition, and demonstrated some level of transformation of assessment practice through the use of technology. This leads us to further explore what this transformation looks like.

To be classified in the Redefinition category (the highest level of the SAMR model aligned with transformation), articles needed to describe how technology was used to create new assessment and feedback practices that were previously not possible without its use. The articles also needed to indicate alignment with one or more principles of good assessment and feedback practice (Nicol, 2009).

All 23 articles in this category described a clear pedagogical intent and a positive impact by affording students opportunities to engage more actively in learning, become self-reliant, confident, 
and able to make judgements about the quality of their own learning (Nicol, 2010). A broad range of technologies were used together with assessment principles including:

- virtual classrooms in remote, resource-constrained areas to clarify standards of performance;

- student-constructed tests, and student-created podcasts and videos, to ensure summative assessment has a positive impact on learning;

- cameras for capturing on-location learning, and open online, collaborative exams to encourage positive motivational beliefs and self-esteem;

- virtual worlds to simulate inaccessible real life experiences and support the development of learning groups;

- social media (Facebook, Twitter, wiki) to encourage interaction and dialogue around learning (peer and teacher-student);

- student response systems to provide information to teachers that can be used to help shape their teaching;

- remote access to Magnetic Resonance Imaging, or student-created digital stories, to encourage 'time and effort' on challenging learning tasks; and

- computer-based visualized quantitative vibrato analysis system to deliver high quality feedback information that helps learners to self-correct.

Alongside the focus on formative assessment, half of the studies in the Redefinition category also focused on developing new approaches to summative assessment. They attempted to capture and grade learning skills, competencies, and dispositions through non-traditional performance such as peer interactions, collaborations, student-created videos, digital story-telling, virtual worlds, and student constructed tests.

\section{Illustrative examples of transformative assessment and feedback practice}

The intervention reported by Drinkwater, Gannaway, Sheppard, Davis, Wegener, Bowen, and Corney (2014) used technology to redefine and facilitate formative assessment and feedback practice in line with Nicol's (2009) principles. This intervention attempted to address the challenge of encouraging active learning in large lecture theatres. Students completed online quizzes before each lecture and software was used to analyze the responses and identify misconceptions. This information fed-forward to inform subsequent interactive question-driven learning. This provided learners with "opportunities to act on feedback (to close any gap between current and desired performance)" (Nicol, 2009, p. 5) and increased the alignment of formative and summative assessments to ensure that "summative assessment has a positive impact on learning" (Nicol, 2009, p. 5). An additional five articles addressed the challenge of engaging large numbers of students during lectures. They reported the collection of instantaneous, anonymized formative feedback with the aid of electronic voting systems, and the consequent increase in formative self, peer and teacherassessment.

A unique example in terms of Redefinition involved students learning the highly nuanced technique of violin vibrato (Ho, Lin, Chen, \& Tsai, 2015). An integrated team developed digital visualizations of sounds that could not be conveyed accurately by expert violinists using sound or movement alone. Students were able to analyze their vibrato skills visually and rapidly hone their technique through self-assessment and self-regulation. The study reports all students made 
remarkable improvements within one week, particularly with hand control and the overall vibrato motion.

\section{DISCUSSION}

The aim of this study was to explore technology enhanced assessment (TEA) and employ existing frameworks to shed light on the potential to enhance or transform student learning. This section discusses the findings and offers insights in relation to the two research questions.

The data showed use of social media (27\%) and LMS (24\%) is consistent with the emphasis on social constructivist approaches to learning and the educational goals of increased collaboration, identified in $37 \%$ (52) of the articles, and a focus on self- and peer-assessment and feedback (also $37 \%$ ). The use of social media and LMS aligns with the principles of good assessment and feedback practice related to encouraging interaction and dialogue (peer and teacher-student), and facilitating the development of self-assessment and reflection (Nicol, 2009). Additionally, social media and LMS technologies can support the task design stage of the assessment cycle, as described by Nicol (2008), for example by providing flexibility in the timing of assessments to give students more control of their learning, and by enabling students to develop knowledge, skills and attitudes from a wide social network.

An example of the use of social media to transform assessment and feedback practice at the Redefinition level of the SAMR model is reported in the article by Demirbilek (2015). In this intervention, wiki and Facebook tools were used to clarify what good performance is through the provision of peer feedback on students' instructional material projects. The data indicated that the use of these social media tools to reflect and provide feedback on other students' projects improved students' critical thinking skills and the quality of the material they produced.

A particularly insightful study trialing the potential of an LMS to transform practice is reported by Glover, Parkin, Hepplestone, Irwin, and Rodger (2015). This exploratory study considered all stages of the assessment cycle (Nicol, 2008) including course and task design, submission, marking and feedback generation, issuing feedback and using feedback. Noteworthy is the article's in-depth focus on the literature, the gathering of evidence to investigate students' perceptions, and critique of the affordances or limitations of the institution's LMS. As a result of this holistic approach, and a clear educational goal to change the assessment culture, the beliefs of students who had previously considered feedback from modular and terminal assessment of little value to their future work were transformed as they began to value feedback and engage in productive online student-tutor dialogue.

However, the results showed that not all articles reported interventions at the Redefinition level. When evaluated against the SAMR model, it appears that the majority of the 139 interventions analyzed transfer conventional assessment practices into a technological environment ( $53 \%$ are at the Substitution or Augmentation level). This aligns with Price and Kirkwood (2014) who found that teaching with technology practices may "favour re-enactments of traditional activities in different media forms" (p. 1). Building on this, our analysis showed that Substitution most often comes with some functional improvement, such as more efficient provision of feedback, and hence the steep gradient to Augmentation in figure 1.

In our study the SAMR model highlights essentially a bell-shaped curve with over $70 \%$ of interventions placed in the middle categories of Augmentation and Modification (figure 1). At these mid-levels of the taxonomy, technology affords functional improvement that has the potential to 
affect student learning; for example, through improvement of student self-regulation and reflection. The higher level goals of using technology to design new tasks previously not possible and redefine assessment and feedback practices were not articulated in examples in these categories.

An example of the potential to move from the enhancement of assessment practices at the Augmentation level to the transformation of assessment practice at the Modification level of the SAMR model is given by Prestridge (2014). She focused on the use of Twitter to investigate how students and instructors interacted, and how this impeded and/or supported the learning process for formative assessment. The results indicated "that student-initiated interaction supported by instructor use of participatory pedagogies enables substantive dialogue ... and that paraphrasing [about course content] was the most common way students made learning active" (p. 101). Noteworthy was the limited student sharing, collaboration, or co-construction of knowledge in this study. The author suggests this may have been due to the lack of a defined assessment task. This suggests that, to unlock the potential of TEA, teachers should be open with students about their goals in relation to TEA and about the wide range of formative activity that counts as assessment and feedback.

This suggests the critical element of effective TEA is being able to discern the nuances between the affordances of specific technologies and how these can support assessment for learning. This involves educators making informed decisions about when and how technologies can enhance and transform learning and assessment practices throughout the assessment cycle, including devising authentic and engaging learning tasks, assessing performance and interpreting results, and using the information acquired to enhance further learning (Nicol, 2008). These connections can become evident, and be supported, through the theoretical lens of the TPACK framework and the SAMR model, together with what is understood about good assessment and feedback practices (Nicol, 2009).

Looking again at the SAMR model, $47 \%$ of articles in this study did describe some form of task redesign and/or redefinition for the purposes of improved student learning (figure 1). In these categories (Modification and Redefinition) we start to get a picture of what transformation of assessment looks like. The most frequently stated goals for assessment in these articles were collaborative learning and dialogue involving multiple forms of feedback. These results indicate that formative peer- and self-assessment for learning is becoming recognized and valued by teachers and students. It is clear that social media, together with LMS technologies, are affording this development by facilitating increased interaction and dialogue around learning, allowing students to take more control of their learning, and promoting student self-assessment and reflection.

Leveraging the affordances of new technological teaching and learning tools and practices continues to present new challenges for teachers. The findings of this study indicate that educators need support to draw upon existing evidence to realize the full potential of TEA. By integrating taxonomies and frameworks, such as the transformation levels of SAMR and the teacher knowledge called for by TPACK, together with principles of good practice in assessment and feedback, we can inform pedagogical design and unlock the potential of TEA.

\section{CONCLUSION AND FUTURE RESEARCH}

Educators in higher education institutions are being urged to exploit the growing availability of technologies, amid high expectations that technology will deliver improvements in student 
learning. However, the evidence that technology alone can achieve this is equivocal and should be prefaced by clear pedagogic intention or design.

Our study concludes that, despite that tendency for educators to use technologies that are represented in the middle range of the SAMR taxonomy, technology is being employed alongside good assessment practices with the intent of improving student learning. TEA is being used extensively for formative peer-learning as part of the assessment task design and feedback stages, and social media and LMS have provided the major affordance through enabling student collaboration and purposeful dialogue.

Future research in this area could benefit from an exploration of the literature in a broader range of disciplines and global reach that explicitly links TEA initiatives to improvements in students' learning. An investigation of success factors in employing TEA, such as in assessment design and purposeful use of technologies, could inform a framework to guide practitioners in good practice to unlock the potential of TEA in particular teaching and learning contexts.

\section{ACKNOWLEDGEMENTS}

This research was conducted as part of the 2015 International Collaborative Writing Group Project. The authors would like to thank Dr. Kelly Matthews and Prof. Mick Healey, and the anonymous reviewers, for their leadership and feedback on earlier drafts of this manuscript.

Trudy Sweeney is Associate Dean (Teaching and Learning) and Senior Lecturer of Digital Media at Flinders University, Australia.

Deborah West is Director of Learning and Teaching and Professor at Charles Darwin University, Australia.

Anthea Groessler is a Learning Designer with the Institute for Teaching and Learning Innovation at The University of Queensland, Australia.

Aeron Haynie is Executive Director of the Center for Teaching and Learning and Associate Professor of English at the University of New Mexico, USA.

Bettie Higgs is Senior Fellow, Teaching and Learning, at University College Cork, and formerly Vice-President for Teaching and Learning; she is currently a Vice-President of ISSOTL.

Janet Macaulay is Professor of Biomedical Education and Director of Education in the School of Biomedical Sciences at Monash University, Australia.

Lucy Mercer-Mapstone is a PhD Candidate at the Sustainable Minerals Institute and a Research Assistant at the Institute for Teaching and Learning Innovation at The University of Queensland, Australia.

Michelle Yeo is Associate Professor and Faculty Development Consultant in the Academic Development Centre at Mount Royal University, Canada.

\section{NOTES}

1. The survey instrument used in this study can be viewed via http://preview.tinyurl.com/zv8gjfx

2. A bibliography of all articles included in the dataset for this study is included in the Appendix to this article. 


\section{REFERENCES}

Boud, D., \& Associates (2010). Assessment 2020: Seven propositions for assessment reform in higher education. Sydney: Australian Learning and Teaching Council.

Demirbilek, M. (2015). Social media and peer feedback: What do students really think about using wiki and Facebook as platforms for peer feedback? Active Learning in Higher Education, 16(3), 211-224.

Drinkwater, M., Gannaway, D., Sheppard, K., Davis, M., Wegener, M., Bowen, W., \& Corney, J. (2014). Managing active learning processes in large first year physics classes: The advantages of an integrated approach. Teaching \& Learning Inquiry: The ISSOTL Journal, 2(2), 75-90.

Ferrell, G. (2012). A view of the assessment and feedback landscape: Baseline analysis of policy and practice from the JISC assessment \& feedback programme.

Ferrell, G. (2013). Supporting assessment and feedback practice with technology: From tinkering to transformation. JISC Assessment and Feedback Programme.

Gibbs, G., \& Simpson, C. (2004). Conditions under which assessment supports students' learning. Learning and Teaching in Higher Education, 1, 3-31.

Glover, I., Parkin, H. J., Hepplestone, S., Irwin, B., \& Rodger, H. (2015). Making connections: Technological interventions to support students in using, and tutors in creating, assessment feedback. Research in Learning Technology, 23.

Grant, B. (2013). Pedagogical, SoTL and higher education journal list.

Higher Education Academy (HEA) (2012). A marked improvement: Transforming assessment in higher education. York: HEA.

Ho,T., Lin, H., Chen, C., \& Tsai, J. (2015). Development of a computer-based visualised quantitative learning system for playing violin vibrato. British Journal of Educational Technology, 46(1), 71-81.

JISC (2010). Effective Assessment in the Digital Age. UK: HEFCE.

JISC (2015). Learning and teaching considerations: [webguide].

Koehler, M. J., \& Mishra, P. (2009). What is technological pedagogical content knowledge? Contemporary Issues in Technology and Teacher Education, 9(1), 60-70.

Mishra, P., \& Koehler, M. J. (2006). Technological pedagogical content knowledge: A framework for teacher knowledge. Teachers College Record, 108(6), 1017-1054.

Nicol, D., \& Macfarlane-Dick, D. (2006). Formative assessment and self-regulated learning: A model and seven principles of good feedback. Studies in Higher Education. 31(2), 199-218.

Nicol, D. (2008). Technology-supported assessment: A review of research. [Unpublished manuscript.]

Nicol, D. (2009). Transforming assessment and feedback: Enhancing integration and empowerment in the first year. Glasgow: Quality Assurance Agency (QAA) for Higher Education.

Nicol, D. (2010). The foundation for graduate attributes: Developing self-regulation through self and peer assessment. Glasgow: Quality Assurance Agency (QAA) for Higher Education.

Nicol, D. (2013). Resituating feedback from the reactive to the proactive. In D. Boud, and E. Molloy (Eds.) Feedback in higher and professional education: Understanding it and doing it well (pp. 34-49). Oxford: Routledge.

Nicol, D. (2014). Guiding principles for peer review: Unlocking learners' evaluative skills. In C. Kreber, C. Anderson, N. Entwistle and J. McArthur, Advances and innovations in university assessment and feedback (pp. 197-224). Edinburgh: Edinburgh University Press.

Oldfield, A., Broadfoot, P., Sutherland, R., \& Timmis, S. (2012). Assessment in a digital age: A research review. Bristol: University of Bristol.

O'Hagan, J. (2015). A Critical Review of Puentedura's SAMR [webpage].

Price, L., \& Kirkwood, A. (2014). Using technology for teaching and learning in higher education: A critical review of the role of evidence in informing practice. Higher Education Research and Development, 33(3), 549-564.

Prestridge, S. (2014). A focus on students' use of Twitter-Their interactions with each other, content and interface. Active Learning in Higher Education, 15(2), 101-115.

Puentedura, R. (2010). Ruben R Puentedura's Weblog: Ongoing thoughts on education and technology. [Weblog]

REAP (2007). Re-Engineering Assessment Practices in Scottish Higher Education.

Tight, M. (2012). Researching higher education. Berkshire: McGraw-Hill Education.

Sweeney, T., West, D., Groessler, A., Haynie, A., Higgs, B., Macaulay, J., Mercer-Mapstone, L., \& Yeo,

M. (2017) Where's the transformation? Unlocking the potential of technology-enhanced

assessment. Teaching Learning Inquiry, 5(1). http://dx.doi.org/10.20343/teachlearninqu.5.1.5 
Vygotsky, L. S. (1978). Mind in society: The development of higher psychological processes. Cambridge, MA: Harvard University Press.

Whitelock, D., Gilbert, L., \& Gale, V. (2011). Technology enhanced assessment and feedback: How is evidencebased literature informing practice? Paper presented at International Computer Assisted Assessment (CAA) Conference, Research into e-Assessment, Southampton, UK, 5-6 July 2011.

Whitelock, D., \& Watt, S. (2008). Reframing e-assessment: Adopting new media and adapting old frameworks. Learning, Media and Technology, 33(3) 153-156.

Copyright for the content of articles published in Teaching \& Learning Inquiry resides with the authors, and copyright for the publication layout resides with the journal. These copyright holders have agreed that this article should be available on open access under a Creative Commons Attribution License 4.0 International (https://creativecommons.org/licenses/by/4.0). The only constraint on reproduction and distribution, and the only role for copyright in this domain, should be to give authors control over the integrity of their work and the right to be properly acknowledged and cited, and to cite Teaching \& Learning Inquiry as the original place of publication. Readers are free to share these materials-as long as appropriate credit is given, a link to the license is provided, and any changes are indicated. 